\title{
AN ESTIMATE OF THE ROUGHNESS LENGTH AND DISPLACEMENT HEIGHT OF SONORAN DESERT VEGETATION, SOUTH-CENTRAL ARIZONA
}

by Hans C. Claassen and Alan C. Riggs

U.S. GEOLOGICAL SURVEY

Water-Resources Investigations Report 92-4065

Prepared in cooperation with the U.S. DEPARTMENT OF ENERGY under Interagency Agreement DE-Al08-78ET44802 


\section{U.S. DEPARTMENT OF THE INTERIOR BRUCE BABBITT, Secretary \\ U.S. GEOLOGICAL SURVEY \\ Dallas L. Peck, Director}

The use of trade, product, industry, or firm names is for descriptive purposes only and does not imply endorsement by the U.S. Government.

For additional information write to:

Copies of this report can be puchased from:

Chief, Hydrologic Investigations Program U.S. Geological Survey Yucca Mountain Project Branch Books and Open-File Reports Section U.S. Geological Survey Box 25046, Mail Stop 421 Box 25425, Mail Stop 517

Federal Center Federal Center Denver, CO 80225-0046 Denver, CO 80225-0425 


\section{CONTENTS}

Abstract--- 1

Introduction --

Purpose and scope-- 1

Description of study area -...- 1

Acknowledgments - -

Measurement techniques -.-_- 2

Data reduction --.

Calculation of $z_{m}-9$

Discussion -

Summary and conclusions---on 15

References cited - 15

PLATE

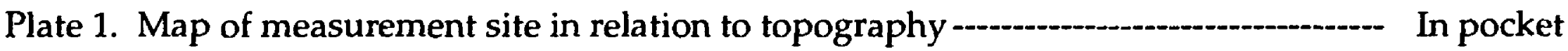

\section{FIGURES}

Figures $1-6$. Wind-velocity profiles for:

1. September 15,1988

2. September 28,1988 -

3. September 30, 1988 - 5

4. February 10, 1989 -

5. February 11, 1989- 7

6. February 13, 1989 -

7. Frequency diagram summarizing $z_{m}$ results from flux calculations $(-0.1 \leq \zeta \leq+0.1)$

8. Frequency diagram summarizing $z_{m}$ results from regression analysis-

\section{TABLES}

Table1. Vegetation inventory and derived characterictics, Sonoran Desert Site, Arizona ----_---- 2

2. Summary of meteorological data and results of calculations -- 10

3. Estimated values of roughness length $\left(z_{m}\right)$ and displacement height $(d)$ 


\section{CONVERSION FACTORS AND RELATED INFORMATION}

\begin{tabular}{rll}
\hline MuItlply & By & To obtaln \\
meter $(\mathrm{m})$ & 3.28 & foot \\
kilometer $(\mathrm{km})$ & .64 & mile \\
square meter $\left(\mathrm{m}^{2}\right)$ & 10.76 & square foot \\
meter per second $\left(\mathrm{ms}^{-1}\right)$ & 3.28 & foot per second \\
watt per meter squared & $4.18 \times 10^{4}$ & gram-calorie per square \\
(watt $\mathrm{m}^{-2}$ ) & & centimeter per second \\
\hline
\end{tabular}

To convert degree Celsius $\left({ }^{\circ} \mathrm{C}\right)$ to degree Kelvin $(\mathrm{K})$ use the following formula:

$$
\mathrm{K}={ }^{\circ} \mathrm{C}+273 \text {. }
$$

To convert degree Celsius $\left({ }^{\circ} \mathrm{C}\right)$ to degree Fahrenheit $\left({ }^{\circ} \mathrm{F}\right)$ use the following formula:

$$
{ }^{\circ} \mathrm{F}=9 / 5\left({ }^{\circ} \mathrm{C}\right)+32 \text {. }
$$

National Geodetic Vertical Datum of 1929 (NGVD of 1929):

A geodetic datum derived from a general adjustment of the first-order level nets of both the United States and Canada, formerly called Sea Level Datum of 1929. 


\title{
AN ESTIMATE OF THE ROUGHNESS LENGTH AND DISPLACEMENT HEIGHT OF SONORAN DESERT VEGETATION, SOUTH-CENTRAL ARIZONA
}

\author{
By Hans C. Claassen and Alan C. Riggs
}

\begin{abstract}
A somewhat unconventional technique using a tethered balloon was used to estimate the roughness length for momentum $\left(z_{m}\right)$ and displacement height $(d)$ for typical Sonoran Desert vegetation. The results of $z_{m}=0.15 \mathrm{~m}$ and $d=0$ are in reasonable agreement with expectation, given the nature and density of the vegetation present.
\end{abstract}

\section{INTRODUCTION}

It has been suggested (Businger, 1986) that measurements of the meteorological fluxes of momentum, sensible heat, and latent heat are best done at heights above ground level determined by either the roughness length $\left(z_{m}\right)$ or the size and shape of vegetation (Raupach and others, 1980). Therefore, estimates of $z_{m}$ and vegetation characteristics are a desirable prerequisite to developing a flux-measurement protocol. Because the literature contains little information on $z_{m}$ for Sonoran Desert vegetation, it is desirable to measure $z_{m}$ and the displacement height $(d)$ associated with Sonoran Desert vegetation.

\section{Purpose and Scope}

This report presents the results of a study made to estimate $z_{m}$ and $d$ for Sonoran Desert vegetation in south-central Arizona. The technique used a tethered balloon alone to measure windspeed, wind direction, temperature, and relative humidity at a single height and thus constitutes a somewhat unconventional datacollection method. Because the objective was limited to a preliminary estimate of $z_{m}$ to determine the height of a permanent meteorological tower, the inadequacies of the method were deemed to be compensated by the minimal instrumentation required. Future measurements that are made on the fully instrumented tower will yield more precise results.

\section{DESCRIPTION OF STUDY AREA}

The site chosen for measurements is located at the northern boundary of Organ Pipe Cactus National Monument, $1 \mathrm{~km}$ west of Arizona Highway 85 and about $150 \mathrm{~km}$ west of Tucson, Ariz. Site elevation is $533 \mathrm{~m}$ above NGVD of 1929 . The site has a $10-\mathrm{km}$ fetch for all headings except from $30^{\circ}$ to $120^{\circ}$, where a $260-\mathrm{m}$ ridge is $1.6 \mathrm{~km}$ distant. The measurement site in relation to the topography is shown on plate 1 .

Sonoran Desert vegetation is characterized by a greater range of height among species than usually occurs in other desert plant communities. A detailed inventory of plant species and dimensions at the site is presented in table 1. 
Table 1.--Vegetation inventory and derived characteristics, Sonoran Desert Site, Arizona

$\left[\mathrm{m}^{2}\right.$, meters squared; $\mathrm{m}$, meters; $\mathrm{s} / \mathrm{S}, \mathrm{s}=$ silhouette area, $\mathrm{S}=$ average area occupied $=$ 4,645 /number of elements, where 4,645 is the total area inventoried]

\begin{tabular}{|c|c|c|c|c|c|c|}
\hline Species & $\begin{array}{l}\text { Number } \\
\text { of plants }\end{array}$ & $\begin{array}{c}\text { Total } \\
\text { area } \\
\text { covered } \\
\left(\mathbf{m}^{2}\right)\end{array}$ & $\begin{array}{c}\text { Percent } \\
\text { of } \\
\text { coverage }\end{array}$ & $\begin{array}{c}\text { Average } \\
\text { height } \\
\text { (m) }\end{array}$ & $\begin{array}{c}\text { Average } \\
\text { diameter } \\
\text { (m) }\end{array}$ & $\mathbf{s} / \mathbf{S}$ \\
\hline $\begin{array}{l}\text { Larrea tridendata } \\
\text { (creosote bush) }\end{array}$ & 178 & 422.36 & 55.67 & 1.15 & 1.74 & 0.0767 \\
\hline $\begin{array}{l}\text { Ambrosia deltoieda } \\
\text { (bursage) }\end{array}$ & 405 & 125.51 & 16.54 & .38 & .63 & .0209 \\
\hline $\begin{array}{l}\text { Ambrosia dumosa } \\
\text { (bursage) }\end{array}$ & 469 & 100.65 & 13.27 & .35 & .52 & .0184 \\
\hline Cercidium spp & 6 & 63.04 & 8.31 & 2.91 & 3.66 & .0138 \\
\hline Krameria grayi & 50 & 27.79 & 3.66 & .39 & .84 & .0035 \\
\hline $\begin{array}{l}\text { Fouqueria splendens } \\
\text { (ocotillo) }\end{array}$ & 5 & 6.03 & .79 & 2.51 & 1.24 & .0034 \\
\hline Not identified I & 14 & 5.62 & .74 & .41 & .71 & .0009 \\
\hline Not identified II & 2 & 6.81 & .90 & .47 & 2.08 & .0004 \\
\hline Opuntia spp & 2 & .71 & .09 & .52 & .67 & .0002 \\
\hline Ferocactus wislizenii & 1 & .22 & .03 & .22 & .48 & .0000 \\
\hline
\end{tabular}

\section{Acknowledgments}

The authors wish to thank David Stannard and Harold Weaver for their many helpful discussions, and Joost Businger for his technical review.

\section{MEASUREMENT TECHNIQUES}

A single tethered balloon with one Atmospheric Instrumentation Research tether sonde was used for meteorologic measurements. The sonde measured windspeed using a lowthreshold cup anemometer (threshold $0.1 \mathrm{~ms}^{-1}$ accuracy $\pm 0.25 \mathrm{~ms}^{-1}$ from threshold to $10 \mathrm{~ms}^{-1}$ ), air temperature and humidity using aspirated wet/dry bulb thermistors, and wind direction using a magnetic compass. Data were obtained at a rate of one measurement every 10 seconds. The sonde also included a fine-wire thermometer to determine sensible heat flux but did not function properly and supplied no useful data. Although synoptic ground-level measurements would have been desirable, the equip- ment was unavailable and an alternative protocol was followed. A description of this protocol follows.

Short-term values were averaged to estimate steady-state conditions. Data-recording intervals of 15 to 30 minutes at fixed heights were used. The initial sequence of heights was from near ground to the usual maximum height of $26 \mathrm{~m}$ or the reverse, in six logarithmically spaced heights. Later, a random-number generator was used to choose the altitude sequence. Two sets of measurements were made: one in September 1988 and the other in February 1989.

The height, diameter, and species of the 1,100-plus plants taller than $0.15 \mathrm{~m}$ were inventoried on a $4,645 \mathrm{~m}^{2}$ plot at the site.

\section{DATA REDUCTION}

Mean windspeed was computed for each logging interval and the results were plotted versus logarithm of height (figs. 1-6). It was assumed that steady-state wind conditions prevailed during a suite of measurements when 


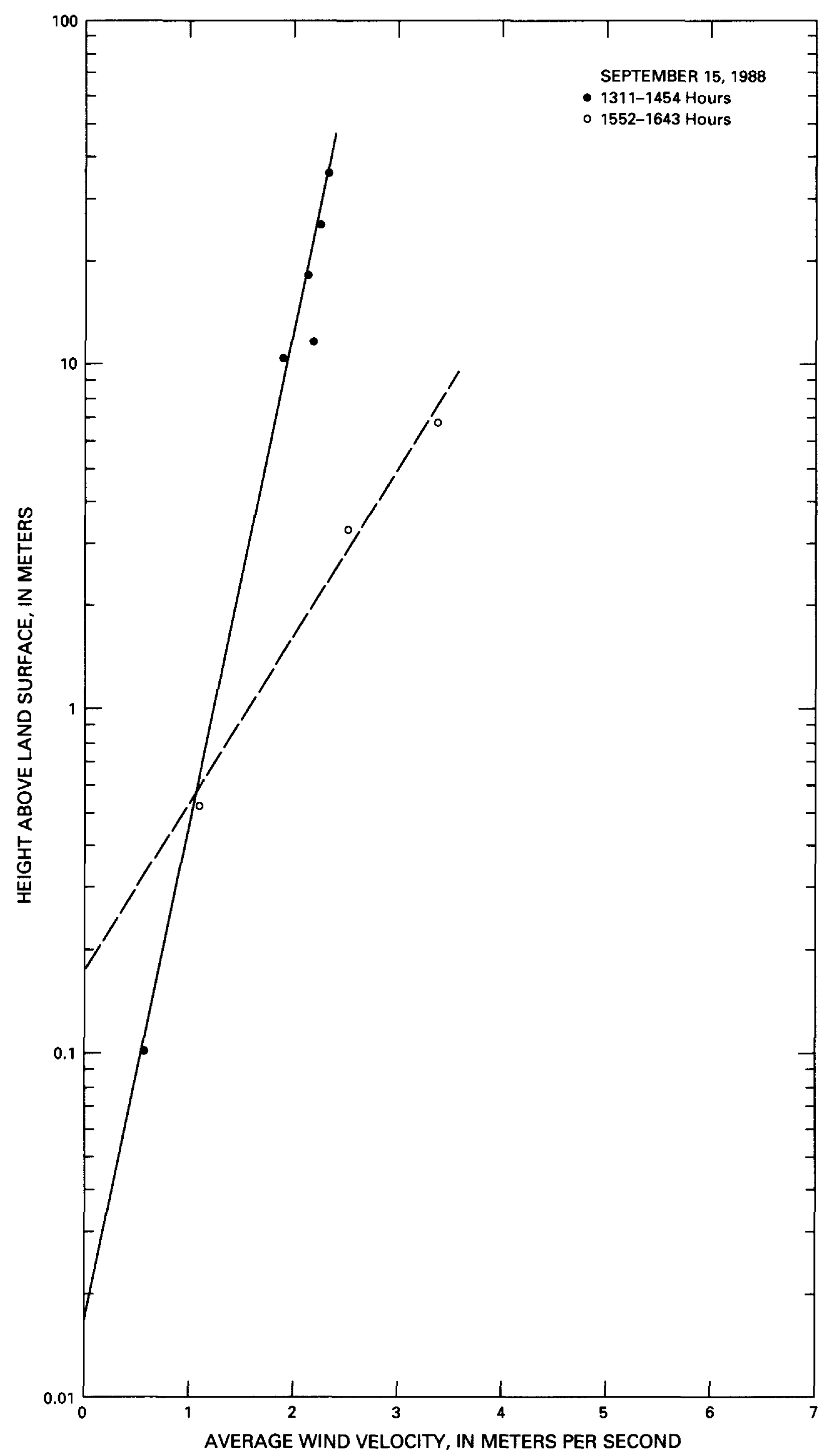

Figure 1.--Wind-velocity profiles for September 15, 1988. 


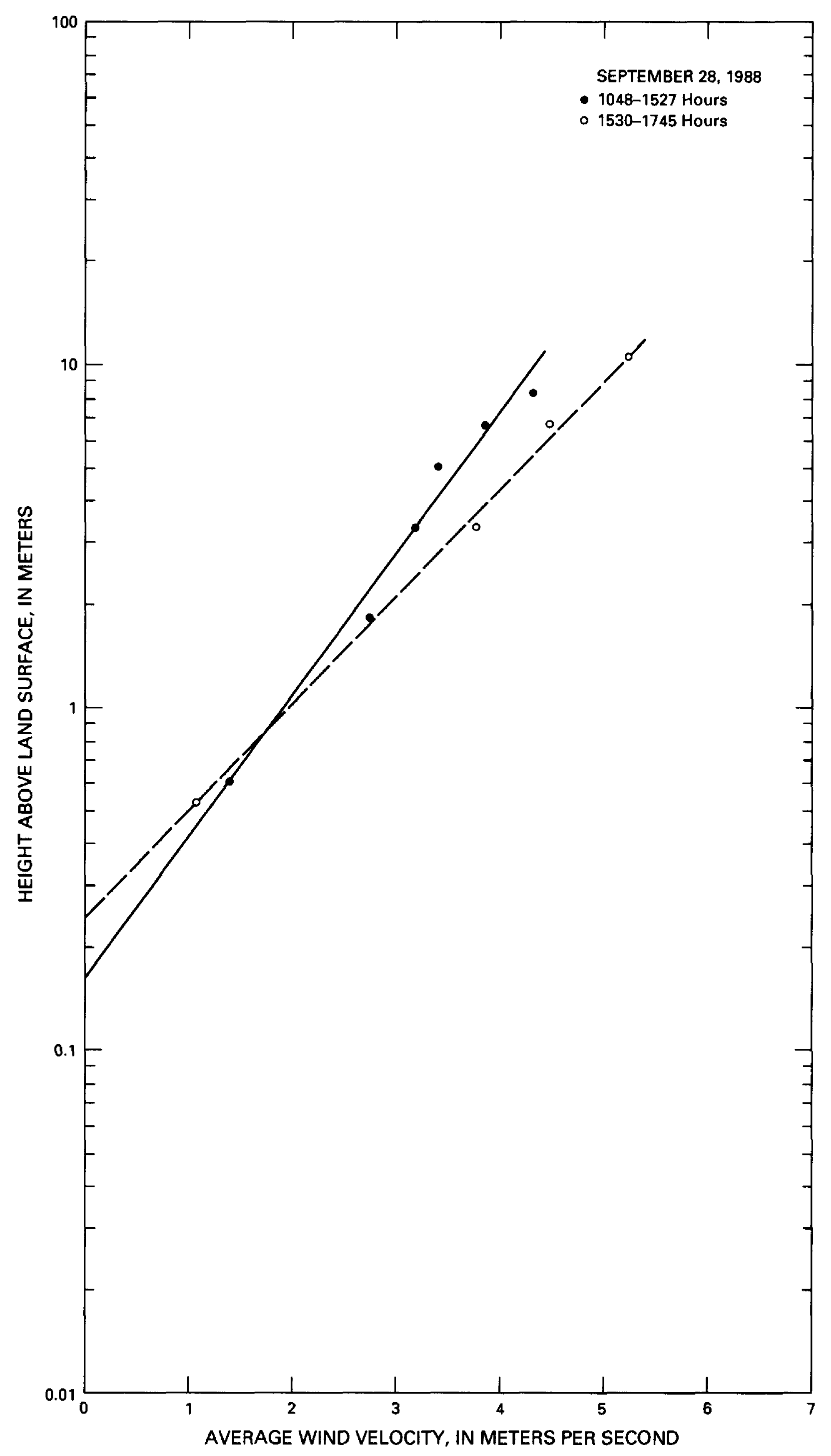

Figure 2.--Wind-velocity profiles for September 28, 1988. 


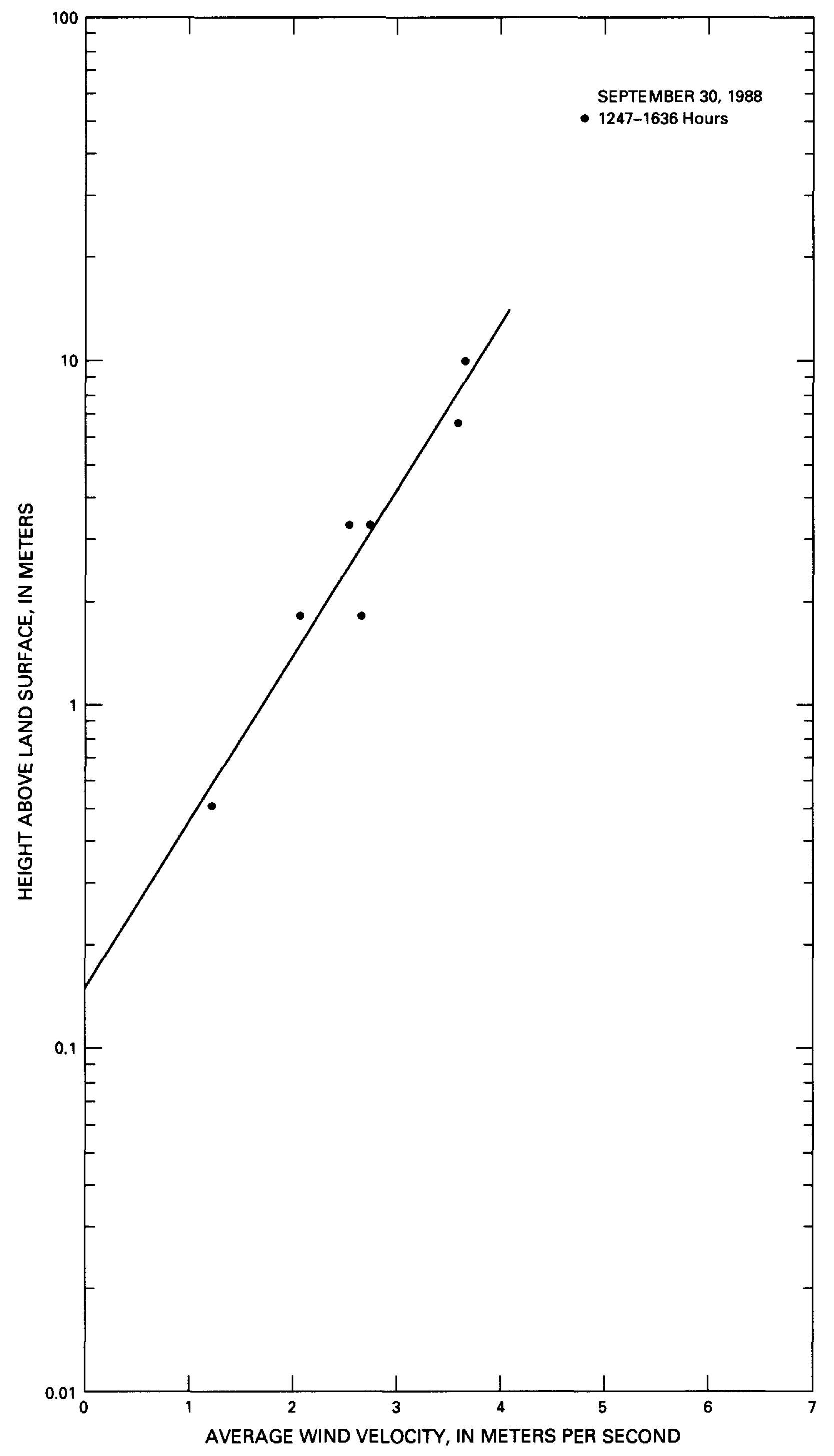

Figure 3.--Wind-velocity profiles for September 30, 1988. 


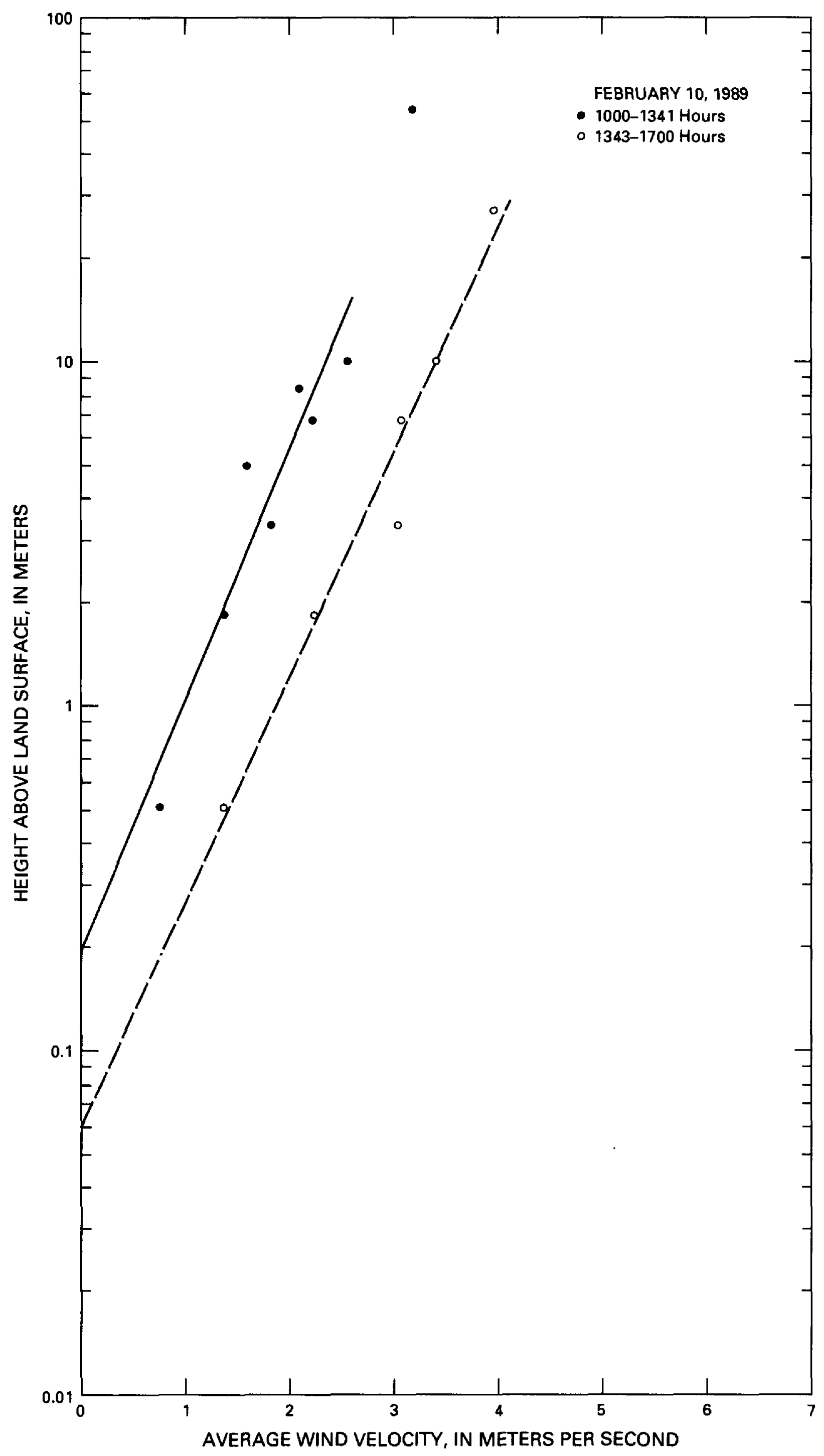

Figure 4.--Wind-velocity profiles for February 10, 1989. 


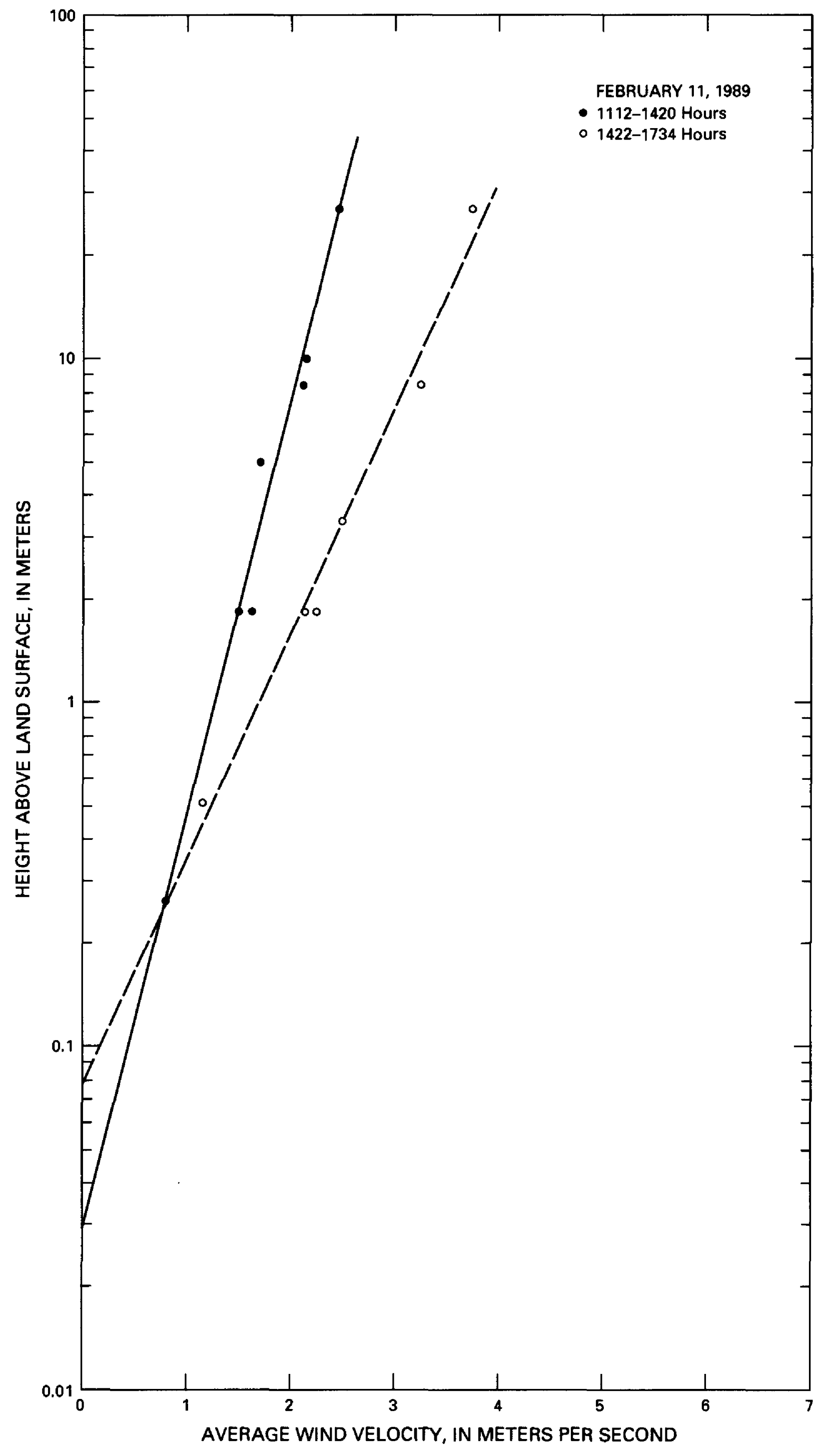

Figure 5.--Wind-velocity profiles for February 11, 1989. 


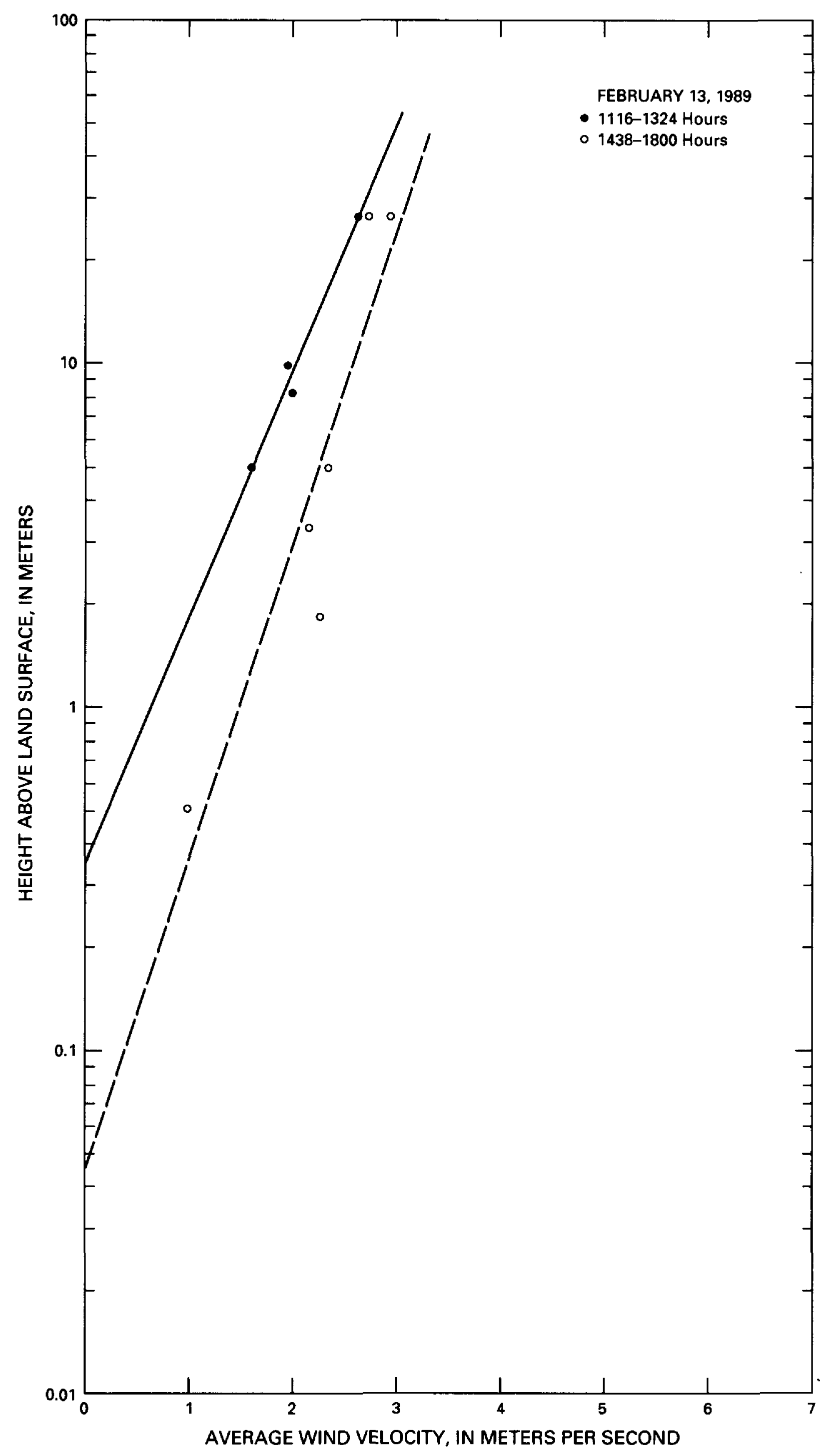

Figure 6.--Wind-velocity profiles for February 13, 1989. 
plots of In height versus windspeed yielded a straight line. A subset of these data, chosen for further analysis, is presented in table 2 .

To minimize the effect of nonstationarity on computing vertical thermal gradients, temperature data were obtained 3 to 4 minutes prior to moving the sonde and 3 to 4 minutes after establishing a new measurement height. The absence of simultaneous measurements at different heights represents a potential source of error, of unknown magnitude, on the estimate of $z_{m}$, but it was hoped this error source was minimized by numerous measurements made under varying conditions. The horizontal windspeed, vertical windspeed-and temperature-gradient values computed from the raw data are presented in table 2 . The vegetation inventory for census plot surrounding the launch site is presented in table 1 . Also included in table 1 are average height $(h)$ and diameter $(D)$ and Lettau's s/S parameter (Lettau, 1969). Lettau's parameter: silhouette area/horizontal-occupancy area, is a measure of the effect of vegetation on the vertical windvelocity profile, hereinafter called the wind profile. The wind profile commonly is used in estimating $z_{m}$.

$$
\cdot \frac{s}{S}=\frac{D h}{4,645 / \text { no. of plants }}
$$

\section{Calculation of $z_{m}$}

The equations that relate momentum and heat fluxes into and out of the vegetation canopy generally assume an idealized, dense canopy over which the wind blows. The distribution of roughness elements that make up the canopy displaces the wind profile upward by an amount $d$ in addition to determining the slope of that profile (Thom, 1971). Therefore, the wind profile (neutral or adiabatic case) is described by:

$$
u=A \ln \frac{z-d+z_{m}}{z_{m}}
$$

where $A$ is a proportionality constant equal to the reciprocal of the slope of the logarithmic wind profile, and the other variables are as previously defined. It follows that

$$
\begin{gathered}
\frac{d u}{d z}=\frac{\frac{A}{z-d+z_{m}}}{z_{m}}\left(\frac{1}{z_{m}} \quad(1)\right) \\
-\left(\frac{z-d+z_{m}}{z_{m}^{2}}(0)\right)=\frac{A}{z-d+z_{m}} .
\end{gathered}
$$

It generally is assumed that momentum flux $(\tau)$ in the surface layer is constant

$$
\tau=\rho K_{m} \frac{d u}{d z}
$$

where $\rho$ is the air density (approximately constant with height) and $K_{m}$ is the eddy diffusivity for momentum. Substituting equation 3 into equation 4

$$
\tau=\frac{\rho K_{m}^{A}}{\left(z-d+z_{m}\right)} .
$$

Solving for $K_{m}$

$$
K_{m}=\frac{\tau\left(z-d+z_{m}\right)}{\rho A}
$$

but $\quad \frac{\tau}{\rho} \equiv u_{*}^{2}$ and $A \equiv \frac{u_{*}}{k}$,

$u_{*}$ is the friction velocity and $K$ is the Von Kármán constant (0.4).

Substituting equations 7 and 8 into equation 6

$$
\begin{aligned}
K_{m} & =\frac{u_{*}^{2} k\left(z-d+z_{m}\right)}{u_{*}} \\
& =u_{*} k\left(z-d+z_{m}\right) .
\end{aligned}
$$




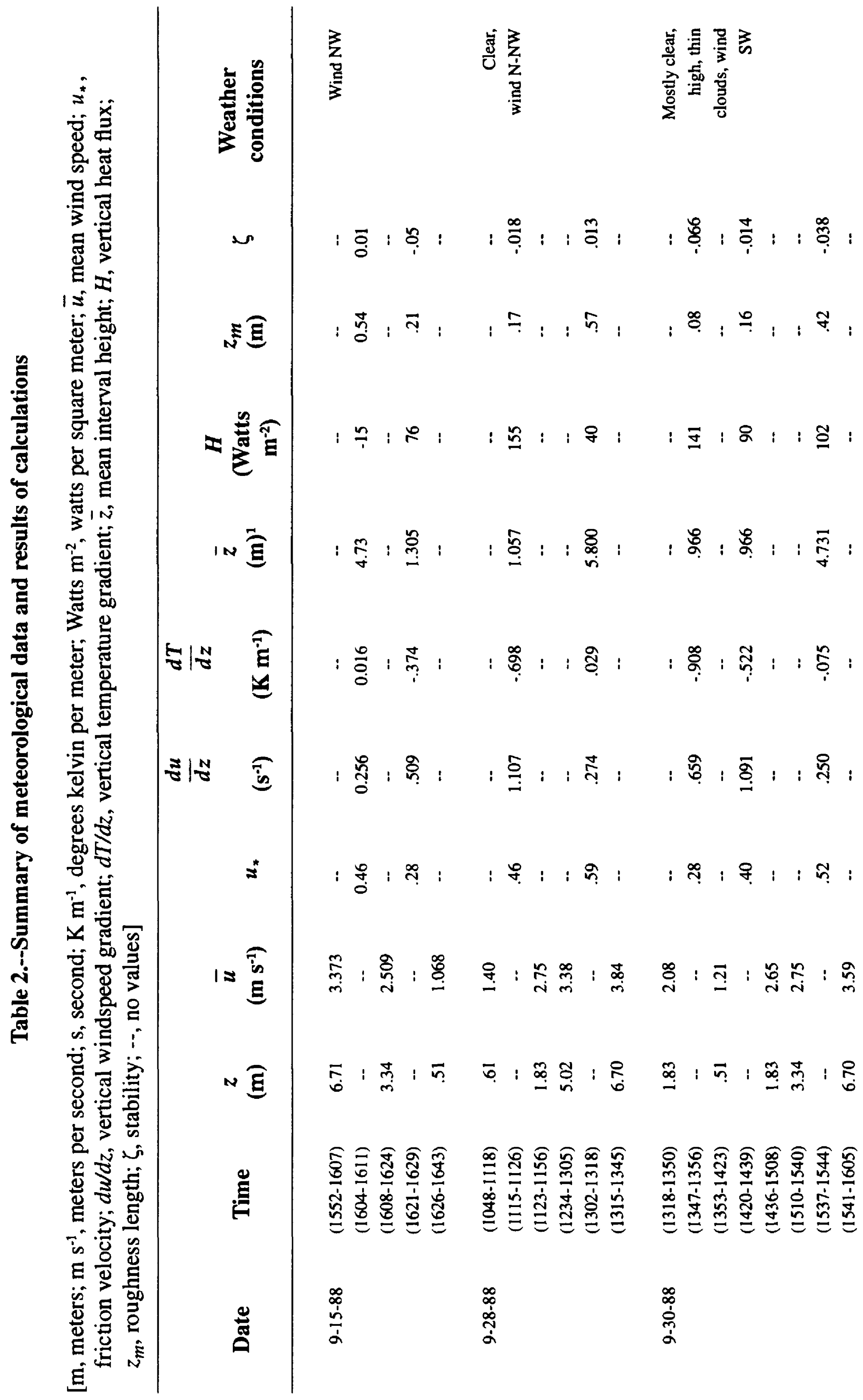




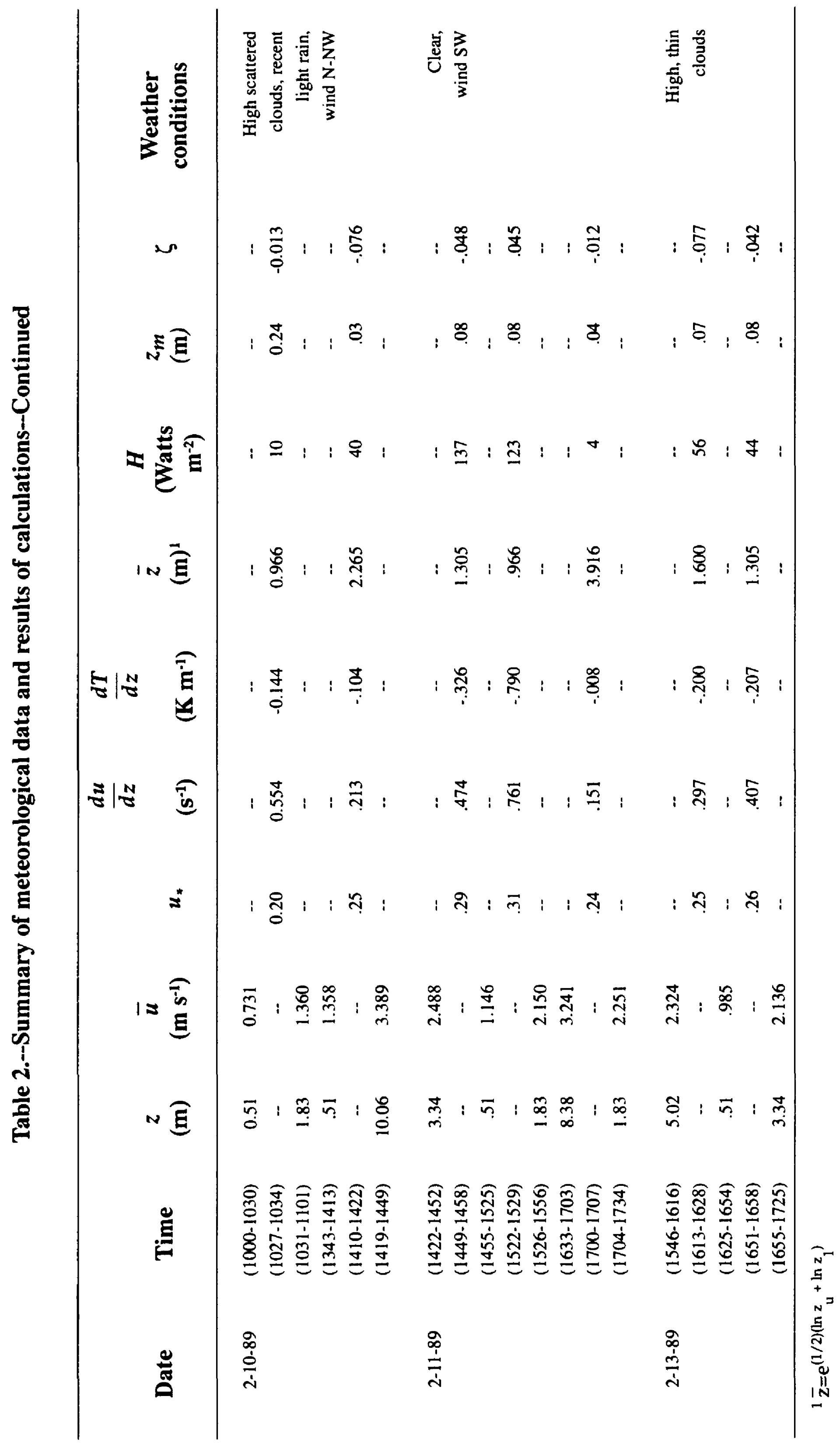


For diabatic conditions $(\zeta$, stability, $\neq 0$ ), the fluxes calculated using equations for neutral conditions must be modified by a flux corrector, $\phi$. Thus:

$$
\begin{aligned}
& \tau_{(\zeta=0)}=\rho K_{m} \frac{d u}{d z} \text { and } \\
& \tau_{(\zeta \neq 0)}=\rho \frac{K_{m}}{\phi_{m}} \frac{d u}{d z} \\
& H_{(\zeta=0)}=-K_{h} \rho C_{p} \frac{d T}{d z} \\
& H_{(\zeta \neq 0)}=\frac{-K_{h}}{\phi_{h}} \rho C_{p} \frac{d T}{d z} \\
& E_{(\zeta=0)}=-K_{v} \frac{d q}{d z} \text { and } \\
& E_{(\zeta \neq 0)}=\frac{-K_{v}}{\phi_{v}} \frac{d q}{d z}, \\
& \underbrace{}_{h}
\end{aligned}
$$

where

$H$ is the heat flux;

$E$ is the water-vapor flux;

$K_{h}$ is the eddy diffusivity for heat, and

$K_{v}$ is the eddy diffusivity for water vapor;

$d T / d z$ is the temperature density gradient; and

$d q / d z$ is the vapor density gradient;

$C_{p}$ is the heat capacity of the air at constant pressure; and

$\phi_{m}$ is the flux corrector for momentum;

$\phi_{h}$ is the flux corrector for heat; and

$\phi_{v}$ is the flux corrector for water vapor.

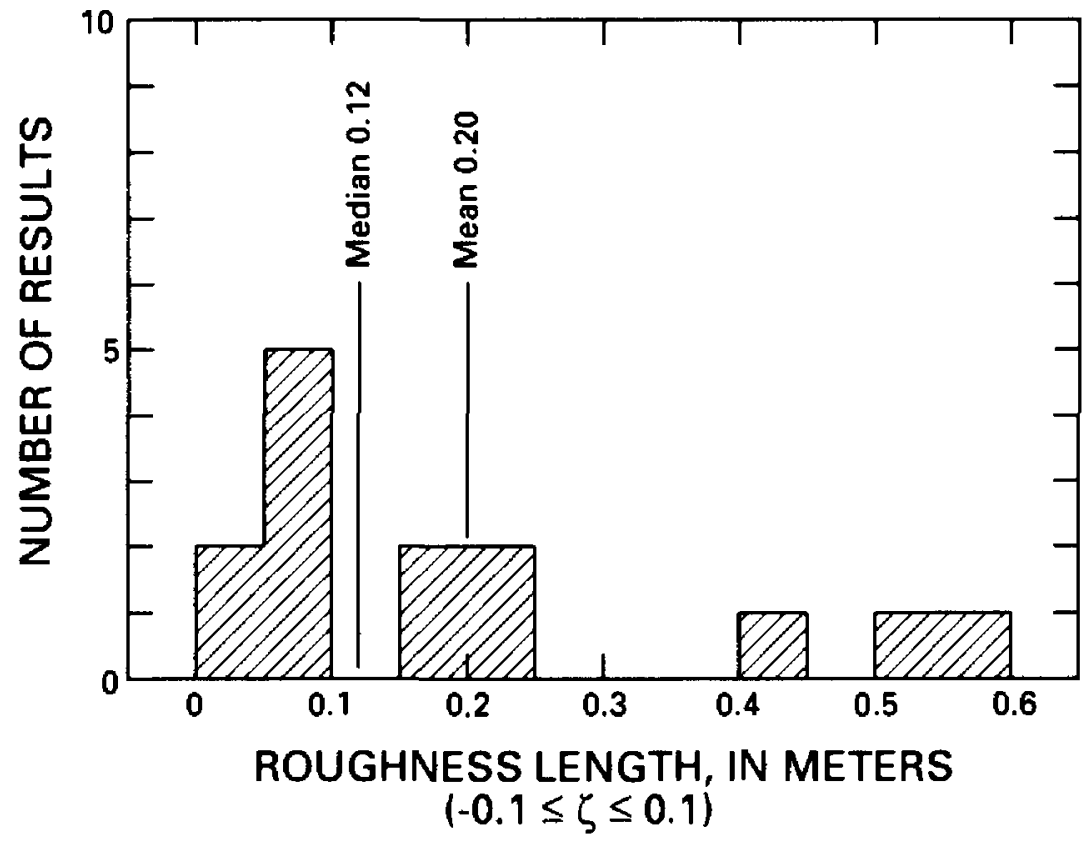

Figure 7.--Frequency diagram summarizing $z_{m}$ results from flux calculations $(-0.1 \leq \zeta \leq+0.1)$.

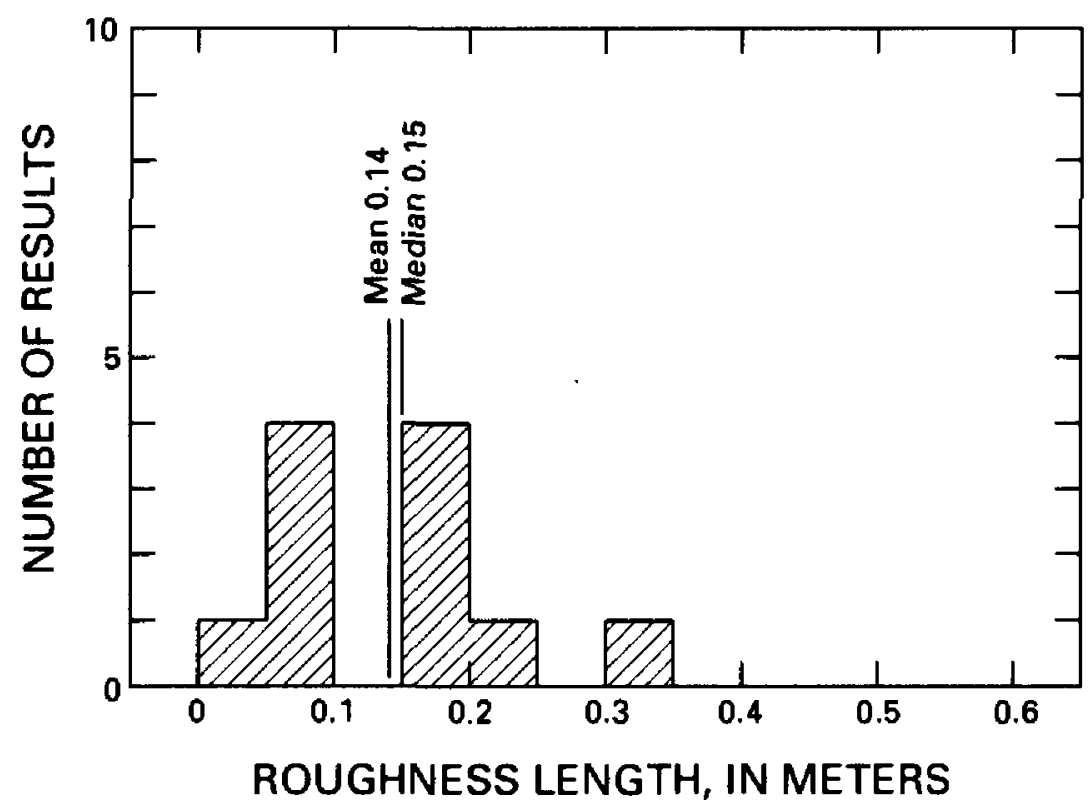

Figure 8.--Frequency diagram summarizing $z_{m}$ results from regression analysis. 
The stability, $\zeta$, is defined as the ratio of convective to mechanical production of turbulence (de Vries and Afgan, 1975)

$$
\begin{gathered}
\zeta=\frac{-k\left(z-d+z_{m}\right) g H}{\rho C_{p} T u_{*}^{3}} \\
\text { For } \zeta>0 \quad \phi_{m}=\phi_{h}=\phi_{v}=1+5 \zeta \\
\zeta=0 \quad \phi_{m}=\phi_{h}=\phi_{v}=1 \\
\zeta<0 \quad \phi_{m}=(1-16 \zeta)^{-.25} \\
\phi_{h}=\phi_{v}=(1-16 \zeta)^{-.50}
\end{gathered}
$$

(Brutsaert, 1982).

Substituting equations 9 and 7 into equation 11, a diabatic influence expression for $u *$ results:

$$
u_{*}=\frac{k}{\phi_{m}}\left(z-d+z_{m}\right) \frac{d u}{d z}
$$

Our computational method for estimating $z_{m}$ is iterative and begins by estimating the following values:

$z_{n l}$, estimated as the $y$ intercept of the linear regressions of $\ln z$ versus $\bar{u}$,

$u_{*}$ estimated as $0.2 \bar{u}$,

$\bar{u}$, the mean windspeed of the adjacent two logged heights,

$\frac{d u}{d z}$, the windspeed gradient, determined as previously described, and

\section{$\frac{d T}{d z}$, the temperature gradient, determined as previously described.}

Equation 9 is used to estimate $K_{m}$ (assumed to equal $K_{h}$ ), equation 13 estimates $H$, equation 16 estimates $\zeta$, equations $17-20$ estimate the diabatic correction factors, equation 21 estimates a new value for $u_{*}$. The process is repeated until no significant changes in $H$ are obtained in successive iterations.
The diabatic profile equation is used to calculate $z_{m}$ :

$$
\bar{u}=\frac{u_{*}}{k}\left[\ln \frac{z+z_{m}-d}{z_{m}}+\psi_{m}\right] .
$$

$\Psi_{m}$ is the diabatic profile correction factor and is related to $\zeta$ by:

for $\zeta \geq 0,-\bar{\Psi}_{m}=-5 \zeta$

for $\zeta \leq 0, \quad-\psi_{m}=2 \ln \left[\frac{1+(1-16 \zeta)^{.25}}{2}\right]$

$$
\begin{aligned}
& +\ln \left[\frac{1+(1-16 \zeta)^{.50}}{2}\right] \\
& -2 \arctan (1-16 \zeta)^{.25}+\frac{\pi}{2}
\end{aligned}
$$

(Brutsaert, 1982). Equations 23 and 24 represent the integrated forms of the flux equations; for example, equations $7,9,11$, and 17 combined and integrated to yield equations 22 and 23. Values of computed $z_{m}$ are presented in table 2. A summary of the resulting computed $z_{m}$ in the form of a bar graph is shown in figure 7 . Those results for stability conditions $-0.1 \leq \zeta \leq+0.1$ (near-neutral) are included in figure 7 . The median and mean values for both data sets are similar and indicate that $z_{m} \approx 0.16 \mathrm{~m}$.

The results from semilogarithmic regressions of the $z$ versus $\bar{u}$ data are shown in figure 8 . These results indicate that $z_{m}=0.14 \mathrm{~m}$. Linear plots of $z$ versus $\vec{u}$ (not shown) suggest $d \approx 0$.

\section{DISCUSSION}

Conventionally, onsite determinations of $z_{m}$ are done in environments with dense vegetation having uniform height to more closely meet assumptions on which the micrometeorological models are based. For these circumstances, some general rules relating vegetation 
height and density to $z_{m}$ and $d$ have been proposed.

Paeschke (1937):

$$
z_{m}=\frac{h}{7.35},
$$

Sellers (1965):

$\ln z_{m}=\alpha+\beta \ln h=2.5+\ln h$

for $z_{m}, h$ in centimeters,

Stanhill (1969):

$$
d=0.64 h,
$$

Lettau (1969):

$$
z_{m}=h(0.5 s / S),
$$

where

$s$ is the average vertical silhouette area of the roughness elements, and

$S$ is the average area occupied by an element.

Otterman and others (1988):

$$
z_{m}=0.5 h\left[1-e^{-s / S}\right] \text {. }
$$

Although the quantity $s / S$ is a simple geometric representation of roughness elements and, hence, contributes to drag force, the silhouette of a roughness element is only one factor that affects resistance to air flow produced by that element. For desert vegetation that has evolved to minimize transpiration, it would not be surprising if the resistance to flow were substantially different from tropical or temperate-zone vegetation of similar $s / S$. Typical drag coefficients for cylindrical, spherical, or hemispherical solid objects range from 0.2 to about 0.5 (Campbell, 1977). The use of 0.5 is evident in equations 28 and 29. One might expect these values to be representative values for vegetation elements composed of dense leaf and branchlets. Much desert vegetation is relatively open and generally is sparsely distributed; Otterman and McCumber (1986) estimate that $s / S$ is less than 0.3 for even dense desert scrub, an estimate in agreement with our measurements (table 1). The observed nature of the predominant vegetation (Larrea, 56 percent; combined Ambrosia spp., 30 percent) would indicate that Larrea presents an open structure whereas Ambrosia approaches the idealized solid object because of a high density of leaves and branches. Thus, Larrea $(s / S=0.0767)$ would exert a different drag than combined Ambrosia spp. (s/S $=0.0393)$. In the results presented in table 3 , it is assumed that all element types act independently and, therefore, their $s / S$ values may be summed. However, most species are relatively ineffective in contributing to the drag, primarily because of their scarcity. It is further assumed in the results in table 3 that the height of the canopy is the weighted (by area of coverage) mean of all species present.

\begin{tabular}{|c|c|c|c|c|c|c|}
\hline \multicolumn{7}{|c|}{ Method of Calculation } \\
\hline $\begin{array}{l}\text { Vari- } \\
\text { able }\end{array}$ & $\begin{array}{c}\text { Paeschke } \\
\text { (1937) }\end{array}$ & $\begin{array}{l}\text { Sellers } \\
\text { (1965) }\end{array}$ & $\begin{array}{l}\text { Stanhill } \\
\text { (1969) }\end{array}$ & $\begin{array}{l}\text { Lettau } \\
\text { (1969) }\end{array}$ & $\begin{array}{l}\text { Otterman } \\
\text { and others } \\
\text { (1988) }\end{array}$ & $\begin{array}{l}\text { This } \\
\text { study }\end{array}$ \\
\hline $\begin{array}{l}{ }^{1} z_{m} \\
{ }^{d} d\end{array}$ & 0.12 & 0.07 & $\overline{0.56}$ & 0.05 & 0.05 & \\
\hline $\begin{array}{l}{ }^{2} z_{m} \\
{ }^{2} d\end{array}$ & .14 & .08 & $\begin{array}{l}- \\
.66\end{array}$ & .07 & .07 & \\
\hline$z_{m}$ & & & & & & ${ }^{0.15}$ \\
\hline
\end{tabular}

Table 3. Estimated values of roughness length $\left(z_{m}\right)$ and displacement height $(d)$ [--, no values]

${ }^{1} h$ is the mean, weighted according to area covered, of the two dominant species $(0.876 \mathrm{~m})$, and $s / S$ is the sum of the three dominant species $(0.1160)$.

${ }^{2} h$ is the mean, weighted according to area covered, of all species present $(1.033 \mathrm{~m})$, and $s / S$ is the sum of all species, acting independently $(0.1382)$.

It seems that the models of Sellers and Lettau underestimate $z_{m}$, and the model of Stanhill may substantially overestimate $d$. The reason for this disagreement may be because of the assumptions present in choice of 0.5 for the drag coefficient, or it may result from an incorrect conceptual model of the canopy. Seginer (1974) developed relations between the atmospheric parameters $d$ and $z_{m}$, and the canopy parameters $C_{D}, a(=s / S h)$, and $l_{h}$ (mixing length at top of the canopy) using Inoue's model (Inoue, 1963). These relations are expressed as follows:

$$
\begin{gathered}
\frac{d}{h}=1-\frac{l_{h}}{k h} \\
\frac{z_{m}}{h}=\frac{l_{h}}{k h} \exp -\left(\frac{4 k^{3}}{l_{h} C_{D^{a}}}\right)^{\frac{1}{3}}
\end{gathered}
$$

If we assume $d \approx 0$ and $z_{m}=0.15, l_{h}=k h$ $\approx 0.413$ for the weighted mean canopy height and 


$$
\begin{gathered}
\frac{z_{m}}{h}=\exp -\left(\frac{4.631}{C_{D}}\right)^{1 / 3}=\frac{0.15}{1.033}=0.145 \\
-1.930=-\left(\frac{4.631}{C_{D}}\right)^{1 / 3} \\
C_{D}=0.64
\end{gathered}
$$

The above-estimated $C_{D}$ is larger than expected for desert vegetation visualized as a collection of solid, right-circular cylinders $\quad\left(C_{D}=0.32\right)$ (Campbell, 1977), but only slightly larger than the estimated value for dense canopies, 0.5 using generalized rules. That $C_{D}$ is substantially larger than the idealized solid-form vegetation is not surprising (Brutsaert, 1982; Seginer, 1974), because the effect of the open structure of the most abundant species, Larrea, is expected to increase turbulence. However, it is surprising that the canopy in the Sonoran Desert seems to behave as if it were a borderline example of the dense, vertically homogeneous, canopy because only 16 percent of the horizontal area is occupied by plants taller than $0.15 \mathrm{~m}$. Plotting our best estimate of $z_{m} / h$ and $C_{D} a h\left(=C_{D} s / S\right)$ on graphs comparing Seginer's (Seginer, 1974, fig. 2) and Inoue's (Inoue, 1963) modeling results indicate reasonable agreement with both models. Because both models assume a vertically homogeneous canopy and, therefore, a value of $l_{h}$ that is constant with height, it may be concluded that the vertical distribution of roughness elements in vegetation of the Sonoran Desert is sufficiently constant for the constant- mixing-length requirement to be appropriate. Seginer's numerical model (Seginer, 1974) attempts to describe the relation between $z_{m} / h$ and $C_{D} s / S$ for sparse canopies where the stress on the ground is not zero. Our results are in reasonable agreement with Seginer's model as well, affirming that vegetation in the Sonoran Desert occupies a borderline position between dense and thin canopy, and may be modeled by using either concept.

\section{SUMMARY AND CONCLUSIONS}

Measurements of vertical wind profile and sensible heat flux estimates were made in Sonoran Desert vegetation using a tethered balloon. The objective was to estimate the roughness length and displacement height for design of a meteorological tower to study particulate and meteorological fluxes.

Although the method used is somewhat unconventional, the results $z_{\mathrm{m}}=0.15 \mathrm{~m} d=0$ are in agreement with expectations. Comparison of results with various general estimation methods indicates that the assumptions made about the aerodynamic properties of vegetation elements may not be true for some Sonoran Desert species. Despite the foregoing, the results presented in this report are in reasonable agreement with both a model that views roughness elements as sparsely distributed and a model that views the roughness elements as homogeneous and densely distributed. Therefore, Sonoran Desert vegetation occupies a position that conceptually is between dense and sparse vegetation.

\section{REFERENCES CITED}

Businger, J.A., 1986, Evaluation of the accuracy with which dry deposition can be measured with current micrometeorological techniques: Journal of Climate and Applied Meteorology, no. 8, p. 1100-1124.

Brutsaert, W., 1982, Evaporation into the atmosphere: Boston, D. Reidel, 299 p.

Campbell, G.S., 1977, An introduction to environmental biophysics: New York, Springer-Verlag, $159 \mathrm{p}$.

de Vries, D.A., and Afgan, N.H., 1975, Aerodynamics of vegetated surfaces: New York, John Wiley, $453 \mathrm{p}$.

Inoue, E., 1963, On the turbulent structure of airflow within crop canopies: Journal of Meteorological Society of Japan, v. 41, p. 317-325.

Lettau, H., 1969, Note on aerodynamic roughness parameter estimation on the basis of roughness element description: Journal of Applied Meteorology, v. 8, p. 828-832.

Otterman, J., and McCumber, M., 1986, Parameterization of albedo, thermal inertia and surface roughness of desert scrub/sandy soil surface: Rome, Italy, International Satellite and Surface Climatology Project, [Proceedings], ESA SPO 248, p. 87-89. 
Otterman, J., Staenz, K., Itten, K.I., and Kukla, G., 1988, Dependence of snow melting and surface-atmosphere interactions on the forest structure: Boundary-Layer Meterology, v. 45, p. 1-8.

Paeschke, W., 1937, Experimentelle Untersuchungen zum Rauhigkeits-und Stabilitäts problem in der bodennahen Luftschicht: Beiträge zur Physik der freien Atmosphaere, v. 24, p. 163-189.

Raupach, M.R., Thom, A.S., and Edwards, I., 1980, A wind tunnel study of turbulent flow close to regularly arrayed rough surfaces: Boundary-Layer Meteorology, v. 18, p. 373398.
Seginer, I., 1974, Aerodynamic roughness of vegetated surfaces: Boundary-Layer Meteorology, v. 5, p. 383-393.

Sellers, W.D., 1965, Physical Climatology: University of Chicago Press., 272 p.

Stanhill, G., 1969, A simple instrument for the field measurement of turbulent diffusion flux: Journal of Applied Meteorology, v. 8, p. 509-513.

Thom, A.S., 1971, Momentum absorbed by vegetation: Quarterly Journal of the Royal Meteorological Society, v. 97, no. 414, p. 414-428.

*U.S. GOVERNMENT PRINTING OFFICE: 1993-774-207/60052

16 AN ESTIMATE OF THE ROUGHNESS LENGTH AND DISPLACEMENT HEIGHT OF SONORAN DESERT VEGETATION, SOUTH-CENTRAL ARIZONA 